\title{
La temporalidad, recurso estratégico en documentos oficiales de derechos humanos en Chile*
}

\author{
Temporality, strategic asset in official documents of \\ Human Rights in Chile \\ Teresa Oteízal ${ }^{1}$ Claudio Pinuer ${ }^{2}$ \\ ${ }^{1}$ Pontificia Universidad Católica de Chile, Facultad de Letras, Departamento de Ciencias del Lenguaje, \\ Santiago, Chile. Correo electrónico: moteizas@uc.cl \\ ${ }^{2}$ Universidad de Concepción, Departamento de Español, Concepción, Chile. \\ Correo electrónico: cpinuer@udec.cl
}

Este trabajo se centra en el análisis de la reconstrucción de las memorias históricas en informes oficiales sobre violaciones a los derechos humanos en Chile (Informe Rettig e Informe Valech). Postulamos que esta reconstrucción se realiza, en parte, a través de la representación simbólica valorativa de la trama temporal en el discurso. De esta manera, las fases temporales se van constituyendo en el discurso desde determinadas valoraciones de juicios de Estima y Sanción Social, de Apreciación y de Afecto con diferentes niveles de compromiso (Teoría de la Valoración). Consideramos que esta representación simbólica valorativa de la trama temporal tiene el potencial de legitimar perspectivas de las memorias históricas y, dado su rol fundamental en el discurso de la historia, se hace necesario revaluar la ubicación de esta dimensión en la red sistémica de valoración.

Palabras clave: teoría de la valoración, subjetividad, discurso de la historia, derechos humanos, Informe Rettig e Informe Valech.

This article focuses on the analysis of the reconstruction of historical memories in official reports of human rights violations in Chile (Rettig Report and Valech Report). We postulate that this reconstruction is realized, in part, through the valorative symbolic representation of the time framework in the discourse. In this way, the temporal phases are constituted from determinate valuations of Social Esteem and Social Sanction jugement, Appreciation and Afect with different levels of engagement (Appraisal Theory). We consider that this valorative symbolic representation of the time framework has the potential to legitimate perspectives of historical memories, and due to its fundamental role in the discourse of history, it is necessary to reevaluate the location of this dimention in the systemic network of appraisal.

Key words: appraisal theory, subjectivity, historical discourse, human rights, Rettig Report and Valech Report.

\footnotetext{
* Este trabajo es parte del Proyecto FONDECYT N 1090464 "Logogénesis valorativa en discurso de la historia".
} 


\section{INTRODUCCIÓN}

Este trabajo se inserta en el estudio de la logogénesis valorativa en el discurso de la historia reciente de Chile y su objetivo principal consiste en analizar los recursos empleados por los autores para construir prosodias valorativas que determinan de diferentes maneras las memorias históricas que existen en el país en relación con la violación a los derechos humanos. En él se presenta un estudio comparativo de dos informes oficiales sobre violaciones a los derechos humanos en Chile, el informe de la Comisión Nacional de Verdad y Reconciliación (Informe Rettig, 1991) y el informe de la Comisión sobre Tortura y Prisión Política (Informe Valech, 2004), prestando especial atención al análisis del Prólogo de este último informe, escrito por el ex Presidente Ricardo Lagos. Ambos informes han sido producidos por iniciativa de los gobiernos concertacionistas que han dirigido al país entre 1990 y 2009 en el contexto del proceso de clarificación de la verdad y justicia sobre las violaciones a los derechos humanos cometidas entre 1973 y 1990 en Chile por la dictadura militar de A. Pinochet.

Se presenta en primer lugar una discusión del marco analítico que informa nuestra investigación y, a continuación, una síntesis y discusión de los principales resultados de investigaciones previas en relación con la construcción de la subjetividad por parte de ambas comisiones (Oteíza, 2009b, en prensa), con el objetivo de precisar la diferenciación y encuentro entre ambos documentos. Para esto presentamos una breve exposición de los recursos lingüísticos que los autores emplean a nivel léxicogramatical y de estrategias discursivas para construir prosodias valorativas en el discurso. Posteriormente se explora con más detalle en el Prólogo del Informe Valech la expresión de prosodias valorativas que se combinan con los significados de la dimensión temporal. Consideramos fundamental la incorporación de esta dimensión en el sistema teórico de la valoración dado el rol crítico que esta puede desempeñar en la reconstrucción de la historia en el discurso y, por lo mismo, presentamos de manera exploratoria su incidencia en el sistema de ACTITUD (AFECTO, JUICIO y APRECIACIÓN) y en el sistema de COMPROMISO (Monoglosia y Heteroglosia). En este punto rescatamos los planteamientos de Hood y Martin (2007), quienes han investigado en un ámbito diferente -introducciones de discursos académicos en el área de educación- el sistema de GRADUACIÓN y su incidencia en la instanciación graduada de las actitudes explicitadas en el discurso. Para estos autores la dimensión temporal se ubica como un subsistema del sistema de GRADUACIÓN, en el sistema de FUERZA como se examina en la segunda sección sobre la dimensión simbólica de la temporalidad y la Teoría de la Valoración. Planteamos que, si bien esta representación parece funcionar de manera adecuada en los registros académicos analizados por Hood y Martin (2007), la dimensión temporal posee un carácter fundamental en el discurso de la historia, ya que los autores realizan una representación más simbólica de la trama temporal incidiendo en la organización del discurso y en la orientación evaluativa del mismo ${ }^{1}$. Esto exige que el estudio de la teoría de la valoración en diferentes tipos de

1 J.R. Martin $(2002,2007)$ se ha referido al carácter global que tiene la dimensión temporal, particularmente en los géneros históricos, con una fuerte impronta cronológica, si bien es necesario tener en cuenta que existen géneros de la historia de carácter más explicativo e interpretativo (C. Coffin 2002, 2003, 2006; J.R.Martin 2003b, 2007; J.R. Martin y D. Rose 2008). 
discursos conlleve la modificación de la red sistémica y el ajuste del modelo teórico, de manera que sea más útil para describir y explicar cómo se van construyendo los patrones valorativos y, por ende, la subjetividad y la intersubjetividad en los discursos de diversos géneros históricos.

Postulamos, de este modo, que existe una manera más representativa de ubicar estos significados en la red sistémica a la que pertenecen, especialmente en organizaciones discursivas en las que el tiempo es parte de la organización del argumento de manera más global y en las que la instanciación de esta dimensión también colabora con la construcción de una monoglosia y heteroglosia desde el punto de vista del sistema de COMPROMISO (ENGAGEMENT), manifestándose como una retórica de valoración simbólica de la trama temporal en el discurso.

Hemos mencionado que el objetivo más amplio en el que se inserta este trabajo guarda relación con las expresiones de subjetividad en el discurso, las cuales también son parte de las construcciones de memorias históricas. Estas memorias de 17 años de dictadura militar en Chile han representado un proceso que para varios sectores de la sociedad ha significado un largo camino de aceptación en lo relativo a los detenidos-desaparecidos y en el reconocimiento de la existencia de la tortura como una práctica sistemática e institucionalizada, como prueba de manera irrefutable el Informe Valech.

En trabajos anteriores (Oteíza 2009b, en prensa) hemos señalado que los eventos que se iniciaron el 11 de septiembre de 1973 son recordados por diferentes sectores sociales y generacionales chilenos como "salvación", "ruptura", "persecución y despertar de la conciencia" y como una "caja cerrada", de acuerdo con el historiador Stern (2006). Estos marcos conceptuales constituyen referentes sociales de comprensión claves para las nuevas generaciones en relación a cómo diferentes actores sociales dan valor y significado al pasado reciente. El último de estos marcos conceptuales lo consideramos particularmente representado en el Informe Rettig (1991), como se menciona en la tercera sección de este trabajo de comparación entre ambos informes, y como esperamos demostrar en el análisis del Prólogo escrito por el entonces Presidente Ricardo Lagos. Los documentos oficiales sobre DDHH en Chile legitiman una memoria histórica que, dependiendo del impacto de estas prácticas discursivas, podrían luego recontextualizarse, por ejemplo, en otros discursos como el discurso pedagógico de la historia en los manuales escolares.

Concordamos con Jelin (2002) en la importancia del proceso de "historizar la memoria" dado que esto implica "la selección y énfasis de ciertas dimensiones y aspectos del pasado que diferentes actores rescatan y privilegian, y de los cambios emocionales e interpretaciones afectivas que esto implica" (2002: 70). Según esta autora, la resignificación de los acontecimientos del pasado no se establece de una vez y para siempre, sino que se va transformando con el tiempo y, por la misma razón, no podemos analizar la dinámica histórica de la memoria como un proceso lineal. Hemos constatado este fenómeno en la forma cómo se representan 'los pasados' y específicamente en la representación de los diferentes actores sociales y de la violación a los DDHH en el Informe Rettig (1991) y en el Informe Valech (2004) que operan como construcciones discursivas de legitimación (van Leeuwen 2008) de 'una' memoria histórica del pasado reciente del país.

En la actualidad, nadie o casi nadie del mundo histórico chileno podría argumentar en contra de la importancia de la significación de estos informes, fundamentalmente 
porque ellos desafían la versión dictatorial del pasado y porque han entregado, hasta cierto punto, una parte de la verdad y la posibilidad de reparación simbólica y monetaria a un gran número de víctimas de las violaciones a los DDHH durante la dictadura de 1973-1990 como sostiene Hiner (2009). Sin embargo, esto también ha implicado un cierre imposibilitador de la justicia y ha dejado en el anonimato a los victimarios, quienes han quedado relegados a actores colectivos indiferenciados e institucionalizados (Dina, CNI, uniformados, agentes de Estado).

\section{Dimensión Simbólica de la temporalidad y la TeORÍA DE la Valoración}

La Teoría de la Valoración (TVA) constituye un desarrollo posterior de la metafunción interpersonal y su instanciación en el nivel lexicogramatical del sistema de Modo desarrollado por Halliday (1994) y luego por Halliday y Matthiessen (2004). Este aporte es el resultado de las exploraciones realizadas principalmente por Martin (1997, 2000, 2003a, 2003b, 2008); White (2000, 2003); Martin y Rose (2003, 2007); Martin y White (2005) y Hood y Martin (2007). De acuerdo con White (2003), el propósito fundamental de esta teoría es ofrecer una reorganización comprehensiva y sistemática de los recursos lingüísticos empleados para valorar la experiencia social considerando al lenguaje más como un conjunto para hacer significados que como reglas para ordenar estructuras (Martin y Rose 2008). Esta teoría ha sido particularmente fructífera en la exploración del discurso de la historia (Achugar, 2008, 2009; Coffin, 2002, 2003, 2006; Oteíza, 2003, 2006, 2009a, 2009b, en prensa; Oteíza y Pinto, 2008, entre otros).

Uno de los cambios de perspectiva analítica en relación a la expresión de la subjetividad en el discurso guarda relación con el examen de la negociación de nuestros sentimientos y no únicamente en cómo el sistema de modo se encarga de sistematizar a nivel lexicogramatical las maneras en que intercambiamos bienes y servicios: "Los significados 'personales' son negociados entre los interlocutores -ellos no son simples expresiones de estados mentales... con la valoración, entonces, la idea básica es cambiar nuestra mirada del intercambio de bienes \& servicios o información a la negociación de sentimientos" (Hood \& Martin, 2007: 741).

La TVA, que opera en el plano discursivo-semántico del lenguaje, permite analizar en conjunto la gramática y el léxico, concibiendo la expresión de la metafunción interpersonal desde una perspectiva conceptual (prosódica) que puede expresarse en el discurso de manera inscrita (explícita) o evocada (implícita). Esto exige necesariamente que se tomen en consideración las realizaciones léxicas junto con las gramaticales, asumiendo que la valoración no se realiza discretamente en el discurso, sino por acumulación de recursos lingüísticos (Halliday, 1994; Hunston y Thompson, 2000; Martin y Rose, 2003, 2007; Martin y White, 2005). Asimismo, esta teoría considera fundamental la posición de los lectores, quienes pueden adoptar estrategias tácticas, complacientes o de resistencia para enfrentar los discursos. De este modo, la posición dialógica de la TVA, inspirada en la visión de Bajtín de la comunicación social, "tiene que ver con los significados susceptibles de negociación entre los emisores y sus receptores reales o potenciales. Todos los enunciados y textos- aun los 
textos escritos monológicos- contienen elementos que juegan un papel de respuesta a enunciados anteriores o de anticipación a posibles objeciones y cuestionamientos" (Kaplan, 2007: 70).

Creemos que esta teoría ofrece un potencial analítico complementario y consistente con una perspectiva de los Estudios Críticos del Discurso (ECD) y con el interés de los investigadores por "el modo en el que el abuso del poder social, el dominio y la desigualdad son practicados, reproducidos, y ocasionalmente combatidos, por los textos y el habla en el contexto social y político" (van Dijk, 2009: 149). Consecuentemente, los mecanismos de perpetuación, generalización y simplificación (van Leeuwen, 1996) que intentan establecer solidaridad ideológica entre autores y destinatarios tienen la capacidad de instaurar un discurso de consenso en el imaginario de la sociedad, así como de legitimar ciertos discursos por sobre otros (van Leeuwen, 2008), como intentaremos demostrar en el análisis del Prólogo del Informe Valech en el que se legitima "una" / "la" memoria del pasado reciente chileno y de la violación a los derechos humanos durante la dictadura militar de 1973-1990.

Hood y Martin (2007) incorporan la dimensión temporal -en el análisis desde la TVA-como un subsistema de Cuantificación que a su vez depende del subsistema de Fuerza. Este planteamiento sistémico de la TVA les permite analizar cómo los escritores académicos pueden anunciar (flag) los significados de actitud mediante la gradación o escala de significados ideacionales (significados categoriales). El planteamiento de Hood y Martin (2007: 753) se reproduce a continuación en la Figura 1:

Figura 1

Dimensión temporal como parte del sistema de GRADUACIÓN (Hood y Martin 2007)

\begin{tabular}{|c|c|c|c|c|c|}
\hline \multirow{7}{*}{ GRADUACIÓN } & \multirow{6}{*}{ FUERZA } & \multicolumn{4}{|l|}{ INTENSIFICACIÓN } \\
\hline & & \multirow{5}{*}{ CUANTIFICACIÓN } & \multicolumn{3}{|l|}{ MONTO } \\
\hline & & & \multirow{4}{*}{ EXTENSIÓN } & \multirow{2}{*}{ PROXIMIDAD } & TIEMPO \\
\hline & & & & & ESPACIO \\
\hline & & & & \multirow{2}{*}{ DISTRIBUCIÓN } & TIEMPO \\
\hline & & & & & ESPACIO \\
\hline & FOCO & & & & \\
\hline
\end{tabular}

La propuesta que presentamos en este trabajo examina la posibilidad de analizar el sistema de COMPROMISO y de ACTITUD como una organización semántica que considera la dimensión temporal de las valoraciones como una configuración retórica más global que permite visualizar la representación simbólica valorativa de la trama temporal en el discurso.

El pasado puede ser clasificado, seccionado y organizado desde una selección ideológica y valorativa determinada, por eso es posible construir diferentes 'pasados' en el discurso, si bien todas las temporalidades pueden ser valoradas desde diversas actitudes y niveles de compromiso. El pasado, así como también las memorias históricas, tiene el potencial de ser organizado en la interpretación como una pluralidad 
de periodos, sólo que la selección y valoración de "cada pasado" en particular determina la legitimación de una memoria y desde allí una visualización del futuro como sociedad, todo lo cual representamos en la Figura 2.

Figura 2

Representación simbólica valorativa de la trama temporal en el discurso y los dominios semánticos de COMPROMISO y de ACTITUD de la Teoría de la Valoración

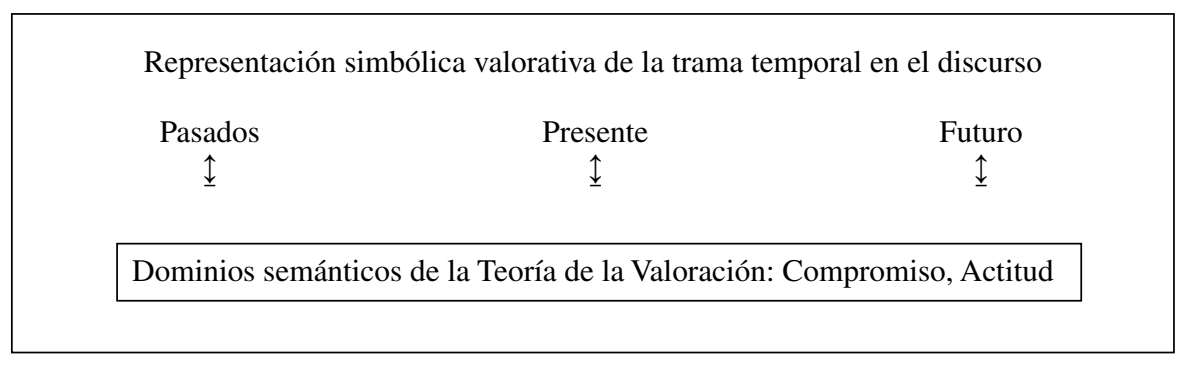

De acuerdo con Martin y White (2005), el marco analítico del sistema de COMPROMISO agrupa a "todas las locuciones que proveen las herramientas para que la voz autorial se posicione en relación con otras voces, y que así se 'comprometa' con ellas y con las posiciones alternativas construidas como parte de un mismo contexto comunicativo" (Martin y White 2005:94). Las estrategias evaluativas pueden entenderse como una monoglosia y heteroglosia u orientaciones más o menos dialógicas (Bajtín 1991) que los autores adoptan para construir una solidaridad ideológica con sus lectores.

\section{ANÁlisis y discusión: Prosodias Valorativas en el Informe RetTig y eN EL INFORME VALECH}

En investigaciones previas (Oteíza 2009b, en prensa) se ha explorado la representación de explicaciones hegemónicas y contrahegemónicas y cómo estas compiten por establecer "sus" memorias en el discurso. Un asunto que nos parece fundamental es que tales posiciones, expresadas en documentos oficiales promovidos y producidos por mandatos presidenciales, tienen el potencial de instalar formas de explicar los eventos que polarizaron al país y representarlos. En estos estudios sobre la construcción de estas prosodias valorativas a nivel discursivo semántico hemos constatado la construcción de significados más o menos heteroglósicos mediante la combinación de recursos linguiísticos como la modulación y polaridad negativa (significados de obligación e inclinación), modalización (significados de probabilidad y frecuencia/ usualidad), recursos de extravocalización (asimilación e inserción) que se conectan en el discurso con la presencia de nominalizaciones acompañadas por un fuerte metadiscurso de actitud por parte de los autores (dominio semántico del COMPROMISO en el marco de la TVA).

En este trabajo se presta especial atención al Prólogo del Informe Valech escrito por el ex presidente R. Lagos. Las secciones analizadas de ambos informes pueden considerarse desde una topología de los géneros históricos (Coffin 2002, 2006; Martin 1997, 2002, 2008; Martin y Rose 2008) como exposiciones en las que se promueve la argumentación de una tesis, planteada discursivamente en torno a causas más que a una temporalidad, por lo cual en ellas existiría una interpretación problemática que 
precisa de justificaciones. El capítulo de Contexto del Informe Valech puede considerarse asimismo como "desafío" (Challenge) dado que el argumento principal de los autores es contravenir la visión política de la existencia de una 'guerra interna' y de un 'enemigo interno' que justificó la muerte, prisión y tortura de miles de chilenos durante la dictadura militar de 1973-1990. En cambio, el Prólogo de R. Lagos del Informe Valech se centra en una fuerte cronología que organiza el pasado en períodos.

\subsection{La Comisión Nacional de Verdad y Reconciliación produjo en el año 1991 el} Informe Rettig. Esta Comisión estaba exenta de individualizar responsabilidades y de hacer justicia y su objetivo principal fue "contribuir al esclarecimiento global de la verdad sobre las más graves violaciones a los derechos humanos cometidas en los últimos años, sea en el país o en el extranjero, si estas últimas tienen una relación con el Estado de Chile o con la vida política nacional, con el fin de colaborar a la reconciliación de todos los chilenos y sin perjuicio de los procedimientos judiciales a que puedan dar lugar tales hechos" (Decreto 355, Artículo Primero).

La Comisión del Informe Rettig comienza presentándose a sí misma en la sección de Exordio desde una fuerte autojustificación, en la cual ofrece una explicación de sus limitaciones y se pone a resguardo frente a la potencial esperanza y anhelo de los chilenos por verdad y justicia. Esto se logra principalmente a través de la estrategia discursiva de una prosodia valorativa dominante ${ }^{2}$ que se construye a través de una polaridad negativa en cláusulas mentales y materiales que funciona como un recurso de contraexpectativa a lo largo de todo el discurso. De este modo, la Comisión se adelanta a lo que la gente esperaba del Informe y de la transición democrática como un todo, y lo que efectivamente sucedió. Este recurso permite la autojustificación de la Comisión desde un punto de vista epistémico (niveles de compromiso con el enunciado) y desde un punto de vista dialógico (contraexpectativa) si se toma en consideración la perspectiva del lector, esto es, la sociedad chilena (Ver Oteíza 2009b para un análisis detallado). A continuación presentamos en la Figura 3 una síntesis desde una perspectiva topológica de la voz de los autores del Informe Rettig.

La Comisión del Informe Rettig marca un énfasis en la imparcialidad de su trabajo y en la inclusión de diferentes posiciones políticas como se aprecia en el breve extracto (1) citado a continuación. En estas palabras se aprecia preocupación explícita por la ecuanimidad a través de una valoración de Estima Social y de Apreciación Social positivas, si bien más adelante, en la sección de Marco Político, se responsabiliza a la extrema izquierda de la violencia y a la derecha de reaccionar frente a esa violencia como una "salida" de la crisis implantada por la izquierda.

(1) Pusimos en nuestro trabajo el propósito más puro de imparcialidad. Fuimos, por consiguiente, objetivos y nos preciamos de haber puesto en ello rigor y comprensión a la vez. Nadie podrá sostener que hemos inclinado nuestra ponderación en función de prejuicios o banderías. En todas nuestras decisiones hubo consenso alentador. (Informe Rettig, Exordio, el destacado es nuestro, aquí y ss.).

Asimismo, es posible apreciar una fuerte asignación de responsabilidad a la sociedad, aspecto que también es visible en el discurso de R. Lagos como se muestra en la sección 3.3. En la Figura 4 se presenta una topología que considera el dominio

\footnotetext{
2 Patrón retórico valorativo en el que el primer elemento de una cláusula u oración domina el significado interpersonal de la misma (J.R. Martin \& P. White 2005).
} 
Figura 3

Representación topológica de la orientación de la Comisión del Informe Rettig: razones para aceptar la 'misión' y sus limitaciones en la asignación de responsabilidades

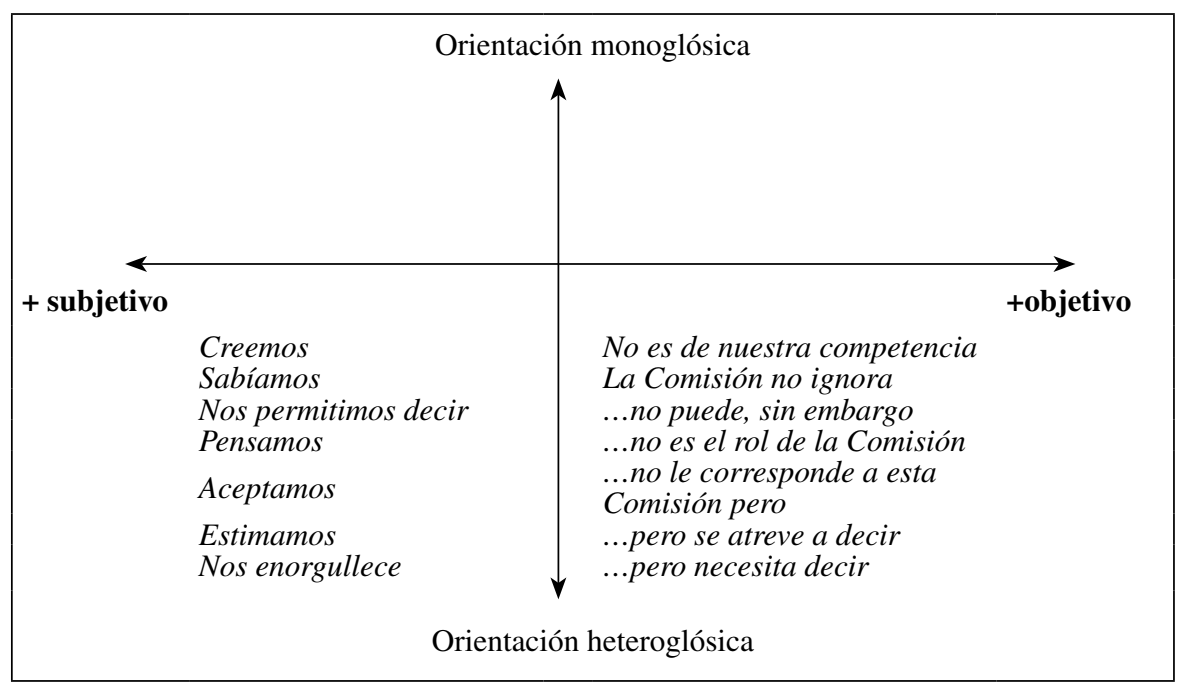

Figura 4

Topología de recursos de la voz autorial de la Comisión del Informe Rettig: responsabilidad de los chilenos

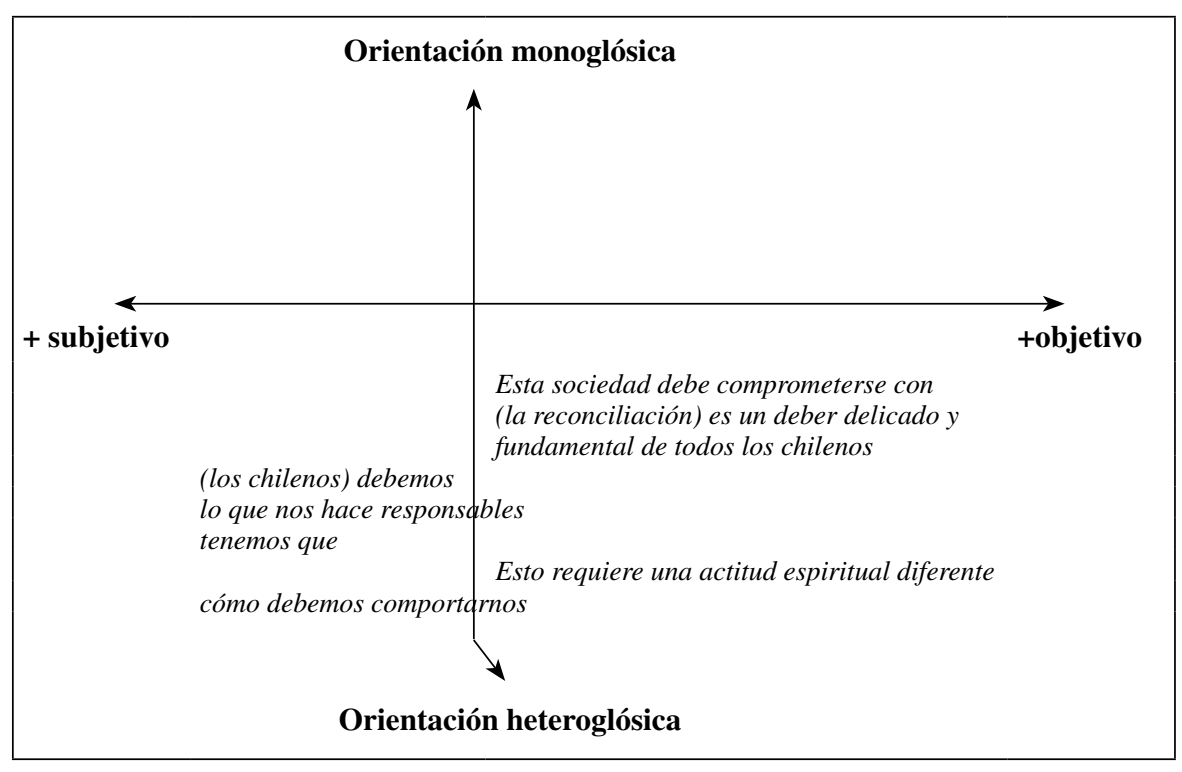


semántico del COMPROMISO (monoglosia-heteroglosia) de los recursos que los autores utilizan para responsabilizar a la sociedad chilena en la violación a los DDHH.

Los autores del Informe Rettig invitan a la sociedad chilena a re-visitar el pasado desde una visión hegemónica (Oteíza 2009b) en la que 'lo que pasó' queda circunscrito a una 'caja cerrada' a la que la sociedad chilena debe aproximarse desde una axiología y una ideología determinadas. Esto implica la presuposición de un deseo de reconciliación, de asumir una responsabilidad moral y convenir en determinadas explicaciones y justificaciones sobre el pasado para construir un 'nosotros' unificado.

\subsection{El Informe de la Comisión sobre Tortura y Prisión Política (Informe Valech 2004).}

Su objetivo fue determinar, de acuerdo con los antecedentes examinados, quiénes fueron "las personas que sufrieron privación de libertad y torturas por razones políticas, por actos de agentes del Estado o de personas a su servicio, en el período comprendido entre el 11 de septiembre de 1973 y el 10 de marzo de 1990" (Presentación de la Comisión, Ministerio del Interior). En su trabajo recogió testimonios de personas que habían padecido tortura y prisión política y redactó varios informes entre los años 2003 y 2005 consignando un total de 28.459 víctimas de prisión política y tortura.

Los autores recurren a la nominalización para construir una evidencia que recontextualiza un momento histórico en oposición a los planteamientos ideológicos de la existencia de una "guerra interna" que fueron compartidos por parte de la sociedad chilena, y que implica, desde la orientación de los autores, asumir una clara solidaridad ideológica con los lectores. Las nominalizaciones, como tipo de metáfora gramatical experiencial, posibilitan la integración jerárquica del conocimiento al construir una tecnicalidad en el discurso (Martin 2007).

La voz de "esta Comisión” está en constante diálogo con múltiples voces que dan legitimidad al capítulo sobre el contexto de la represión política. Es evidente la fuerte construcción heteroglósica (o polifónica) del discurso del Informe Valech mediante la inserción de testimonios de las víctimas de la represión política y de la tortura, de Bandos de la Junta Militar, Decretos de los Consejos de Guerra, publicaciones de diversos medios, documentos de organismos que defendieron los derechos humanos durante la dictadura de Pinochet, Libro Blanco junto con la alusión al "presunto Plan $Z$ ', entre muchos otros. Así, el documento se valida fundamentalmente a través de recursos de extravocalización de inserción y asimilación (White 2000) en conjunto con la estrategia retórica de presentar nominalizadamente los antecedentes y condiciones que construyen las evidencias. Todas estas formas de extravocalización son procedimientos de intertextualidad que los autores van evaluando por vía de la inclusión de un metalenguaje de actitud explícito (Oteíza en prensa), como puede apreciarse en los siguientes ejemplos:

(2) Ha quedado establecido que no había un enemigo a quien entregar secretos ni operaciones que pudieran haber sido objeto de ayuda (...). (Informe Valech, Contexto: 170)

(3) Considerando los hechos expuestos hasta ahora, no sorprende constatar que José Cánovas Robles, el juez designado presidente de la Corte de Apelaciones de Santiago en 1974, al rememorar el desempeño del Poder Judicial durante el régimen militar, concluyera en sus Memorias de un magistrado (1989): En resumidas cuentas, las garantías de impunidad que el Poder Judicial-por propia 
iniciativa o presionado por las autoridades del Ejecutivo- ofreció a los agentes de la represión, alentaron la perpetuación e intensificación de la prisión política y la tortura (...). (Informe Valech, Contexto: 174).

En el Informe Rettig los autores explicitan un manifiesto discurso deóntico; en cambio en el Informe Valech, escrito después de más de una década y en un momento político y social diferente que permitió una relativa apertura a la asignación de responsabilidades, la Comisión no construye un discurso en el que responsabiliza a la sociedad chilena, sino que procura conducir al lector a reconocer y evaluar la masiva evidencia de las atrocidades de la tortura practicada institucional y sistemáticamente en el país. Los autores invitan a mirar el pasado no desde el arrepentimiento, sino desde el reconocimiento de las pruebas masivas de tortura y prisión política como una práctica institucionalizada por parte de agentes de Estado u otros en representación del mismo (Ver Oteíza en prensa para un análisis más detallado).

Los informes oficiales sobre violaciones a los DDHH analizados son parte de un mismo proceso con orientaciones ideológicas similares, esto es, se producen en el marco de una 'política de la memoria' de los gobiernos concertacionistas que se circunscribió al principio de gobernabilidad y a una democracia de los acuerdos y de "lo posible", lo que implica necesariamente una interdiscursividad o intertextualidad constitutiva entre los documentos (Fairclough 2003). En la sección 3.3., mediante el análisis del Prólogo del Informe Valech, esperamos mostrar la manera en que la organización temporal se construye desde determinadas valoraciones en estos documentos que constituyen sistemas de apreciación sobre la memoria histórica del país.

3.3. Prólogo de Ricardo Lagos al Informe Valech (2004). En esta fuente, así como en la Presentación del Informe Rettig, las referencias temporales aparecen con frecuencia. Concordando con lo planteado por N. Lechner (2006: 497), estas contribuyen a construir una representación simbólica de la realidad que se estructura como una trama espacio-temporal. R. Lagos construye su argumento como un camino de sanación desde una posición de Adjudicador (Coffin 2002, 2006) que se permite hacer valoraciones de Estima Social y de Sanción Social. R. Lagos construye este proceso de sanación como un trayecto que tiene como logro último la recuperación de la memoria, destacando, mediante una valoración de juicio de Sanción Social positiva, la capacidad de los chilenos de aprendizaje de los errores del pasado y la capacidad de los mismos para recuperar la unidad y reconciliación.

\section{(4) La recuperación de la memoria.}

En su casi bicentenaria historia, Chile ha tenido pocos quiebres tan profundos y dolorosos como el de 1973. Ninguno ha sido tan crudamente investigado como este último. Ello es sanador del cuerpo y el alma de nuestro país, y puede servirnos para fortalecer el sentido de pertenencia a una comunidad que es capaz de aprender de sus errores y de superar divisiones que en un determinado momento parecieron irreparables. (Informe Valech, Prólogo).

El golpe de Estado de 1973 es nombrado con el recurrido eufemismo de quiebre de la democracia y, de manera similar a como se plantea en el Informe Rettig, se responsabiliza a la sociedad chilena como un todo, la cual es evaluada con valoraciones de ACTITUD de Sanción y Estima Social negativas: 
(5) Las lecciones básicas.

Lo he dicho en varias ocasiones: el quiebre de la democracia y de las bases de nuestra convivencia se produjo en medio de tormentas políticas e ideológicas que no fuimos capaces de controlar. (Informe Valech, Prólogo).

Así también, esta idea se refuerza en el extracto (6) en el que se alude a este pasado del cual todos debemos responder y en el que no se distingue con claridad el gobierno de la Unidad Popular de la dictadura militar de A. Pinochet. Del quiebre de la democracia todos somos responsables dado que no supimos hacernos cargo de la crisis. El pasado de la crisis del gobierno de S. Allende se fusiona con el golpe militar y la violación a los DDHH a través de la estrategia retórica de generalizar momentos sociales de diferente naturaleza representados como un capítulo o fase de la historia de los chilenos y en la capacidad de la sociedad chilena (juicio de Estima Social de capacidad positiva):

(6) El camino de hacernos cargo de este pasado ha sido largo, difícil, complejo. Asumir la cruda verdad de lo ocurrido y la responsabilidad de lo obrado, no ha sido fácil para ningún chileno. (Informe Valech, Prólogo).

Como se podrá comprobar en los extractos (7) y (8), R. Lagos, aunque reconoce la responsabilidad de los agentes de Estado, considera que son el Estado y la sociedad como un todo quienes deben finalmente responsabilizarse de las violaciones a los DDHH en la dictadura militar de A. Pinochet. R. Lagos nos invita a que como sociedad chilena reconozcamos el desvarío y la pérdida de rumbo. Este pasado es representado como un abismo, casi como una laguna mental, como un paréntesis en nuestra senda histórica que ahora retomamos. Con estas palabras, R. Lagos valora desde un juicio de Apreciación Social positiva nuestro pasado más lejano entendido como tradición histórica, en tanto que el pasado reciente es valorado desde una Sanción Social negativa. Lo que la sociedad chilena reconoce y reivindica es a las víctimas y para lo cual, según la voz de Adjudicador de R. Lagos, ya hemos alcanzado la fortaleza moral necesaria que nos permite vivir en armonía. De este modo, R. Lagos establece un cierre a lo planteado por la Comisión del Informe Rettig en 1991 en relación a la necesidad de una espiritualidad distinta requerida a la sociedad chilena para enfrentar su pasado traumático reciente.

(7) El reconocimiento de este triste capitulo de nuestra historia permite que todos los chilenos nos sintamos hoy parte de una misma comunidad y de un mismo destino. Este reconocimiento permite sentir que nuestras instituciones armadas nos pertenecen a todos los chilenos. Reconocer el desvario y la pérdida del rumbo que en un momento del pasado permitieron que las instituciones armadas y el Estado se apartaran de su tradición histórica, de sus propias doctrinas que las vieron nacer y desarrollarse, es la condición para que retomemos la senda de siempre trazada por los fundadores de la República. (Informe Valech, Prólogo). 
(8) El Estado de Chile ha de volcarse hacia ellos [víctimas de las violaciones a los $\mathrm{DDHH}]$ y obtener su perdón para la sociedad que los hirió. Esta debe imbuirse de lo ocurrido para poder mirar limpiamente el futuro. Si reconstruir la verdad ha sido una ardua tarea para esta Comisión, emplearla para la Reconciliación Nacional es un delicado y fundamental deber de todos los chilenos. (Informe Valech, Prólogo).

Como puede apreciarse en los extractos (7) y (9), R. Lagos evidentemente retoma la conclusión fundamental a la que llega la Comisión Valech luego de realizar su trabajo sobre la práctica institucional del Estado de la tortura, pero la sitúa como ajena a la tradición histórica de Chile y, por lo mismo, se enfatiza el carácter anómalo de este pasado de la historia del país.

(9) La conclusión es clara e insoslayable: la prisión política y la tortura fue una práctica institucional de Estado, absolutamente inaceptable, y por completo ajena a la tradición histórica de Chile. (Informe Valech, Prólogo).

(10)Se terminó el silencio, se desterró el olvido, se reivindicó la dignidad. Pero ello requiere algo más. Si está comprometida la responsabilidad de los agentes del Estado, lo que corresponde es que el Estado responda por ello, lo cual implica adoptar medidas que ayuden a mitigar los efectos del dolor causado. (Informe Valech, Prólogo).

(11)Con el reconocimiento a las víctimas de prisión política y tortura completamos un capítulo por el cual teníamos que pasar. (Informe Valech, Prólogo).

En (10) y (11) el énfasis se dirige a las víctimas y en el establecimiento de medidas materiales y simbólicas de reparación, así como también es evidente el deseo de que no se "reabran heridas", lo que implica una política de reconciliación y de evitar la búsqueda de culpables. Se aprecia un cuidado explícito en no ofender a las Fuerzas Armadas que pertenecen a todos los chilenos (extracto 7). Paradojalmente, en el discurso con que R. Lagos reivindica a las víctimas, son ellas mismas las que aparecen como responsables del silencio que debe haber de sus testimonios por 50 años y, por lo tanto, son ellas también las que imposibilitan que se haga justicia ${ }^{3}$.

Este pasado, a diferencia del pasado histórico, es construido desde una valoración negativa como un paréntesis anómalo en que Chile, como un todo, cayó en un abismo, en un desvarío. Así, temporalidad y valoración se van entremezclando en el discurso y van construyendo las diferentes fases de este pasado. Sin embargo, en el camino de hacernos cargo de este pasado, las memorias han quedado transformadas en "la" memoria y la armonía entre los chilenos construida únicamente en torno al reconocimiento de las víctimas y de la práctica institucional y sistemática de la tortura durante la dictadura militar de Pinochet. A continuación se presenta en la Figura 5 una síntesis de esta construcción metafórica del camino de sanación y del término del silencio.

\footnotetext{
3 En relación a las "víctimas", Stubbs (2009) considera que típicamente éstas no son debidamente analizadas sino que son presentadas como víctimas idealizadas o indiferenciadas. Stubbs plantea que tenemos que problematizar las nociones de víctima/perpetrador y que los significados de cada uno son moldeados por las concepciones de las comunidades a las que pertenecen. Se precisa un modelo teórico más claro para entender la victimización.
} 
Figura 5

'El camino de sanación', 30 años de silencio

\begin{tabular}{|c|c|}
\hline \multicolumn{2}{|c|}{ Presidente Lagos como un Adjudicador } \\
\hline Pasados & Presente Futuro \\
\hline $\begin{array}{l}\text { ¿Cómo pudimos vivir } 30 \text { años de } \\
\text { silencio? }\end{array}$ & $\begin{array}{l}\text { La entereza de las víctimas y sus familiares (...) } \\
\text { impidió que ese silencio se convirtiera en olvido }\end{array}$ \\
\hline $\begin{array}{l}\text { Durante la dictadura el silencio era } \\
\text { consecuencia del miedo }\end{array}$ & La madurez de Chile \\
\hline $\begin{array}{l}\text { Todo ello estuvo cubierto durante } \\
\text { mucho tiempo por un espeso e insano } \\
\text { silencio }\end{array}$ & $\begin{array}{l}\text { (Informe Valech) expresión de la fortaleza moral } \\
\text { de Chile }\end{array}$ \\
\hline En esos oscuros días de ayer & La fortaleza moral de Chile \\
\hline $\begin{array}{l}\text { La ruptura de la institucionalidad y } \\
\text { la arbitrariedad y el terror }\end{array}$ & $\begin{array}{l}\text { Se terminó el silencio, se desterró el olvido, se } \\
\text { reivindicó la dignidad. }\end{array}$ \\
\hline $\begin{array}{l}\text { Las heridas de nuestra alma } \\
\text { nacional }\end{array}$ & Ha sido un largo, paciente y complejo camino \\
\hline \multirow{3}{*}{ La tradición histórica de Chile } & Hemos recuperado la necesaria armonía \\
\hline & Hoy podemos ver con serenidad nuestro pasado \\
\hline & $\begin{array}{l}\text { Tenemos la fortaleza suficiente para transformar el } \\
\text { dolor en memoria y la memoria en unidad nacional, } \\
\text { en un futuro compartido. }\end{array}$ \\
\hline
\end{tabular}

Finalmente, para cerrar esta sección, presentaremos algunos ejemplos de la amplia gama de recursos lingüísticos que R. Lagos utiliza para plasmar en el discurso la organización simbólica de la trama temporal:

a. instancias temporales graduadas: durante mucho tiempo;

b. referencias al pasado a través de un adjunto temporal: hoy podemos ver...;

c. referencias al pasado en flexiones verbales y formas aspectuales perfectivas de

los mismos: Hemos recuperado la necesaria armonía entre la sociedad y sus instituciones armadas; se termina el silencio, se desterró el olvido, se reivindicó la verdad; o mediante el presente menos marcado y común en las nominalizaciones, pero que permite a R. Lagos funcionar como un Adjudicador (intérprete) que juzga moralmente la capacidad de los chilenos: la madurez de Chile;

d. referencias a un futuro hipotético del que se han evitado circunstancias negativas mediante el empleo del pretérito imperfecto de subjuntivo: La entereza de las víctimas y sus familiares (...) impidió que ese silencio se convirtiera en olvido.

Por otro lado, es posible apreciar también que la temporalidad no puede disociarse del sistema de COMPROMISO y que de alguna manera ambos sistemas de significados son puestos en relación en el discurso (concepto de coupling, Hood y Martin 2007; Martin 2008) para construir significados valorativos como en: ¿Cómo pudimos vivir 30 años de silencio? en el que el finito modal pudimos alude a un significado heteroglósico (nosotros) modalizado, y lo vivido se expresa temporalmente en un grupo nominal que permite la construcción de la metáfora léxica. 
El silencio es así graduado y construido como un momento particular que luego llega a su término con Hoy podemos ver con serenidad muestro pasado y en ha sido un largo, paciente y complejo camino. La metáfora léxica del camino, que claramente se refiere a una dimensión temporal de uno de los 'pasados', retoma y cierra lo expresado por la Comisión Valech en la Presentación del Informe en la que se alude a una conspiración de silencio.

La reconstrucción de la temporalidad del "pasado" se realiza desde posiciones que legitiman perspectivas de las memorias históricas. El mirar este pasado (lo que implica necesariamente la existencia de "otros pasados") conlleva la idea de una "caja cerrada" que revisitamos desde determinadas miradas axiológicas (o cosmologías axiológicas sostendrían Maton 2007 y Martin 2007) e ideologías legitimadas.

Como sostiene Vasilachis de Gialdino (2007) la reiteración de las metáforas léxicas posibilita la naturalización del conocimiento conceptual haciendo muy difícil su reemplazo. Por ejemplo, la expresión la madurez espiritual de Chile es una nominalización de un estado espiritual que supone, por un lado, una evaluación de Sanción Social positiva por parte de quien adjudica (R. Lagos) y, por otro, el presupuesto de que previamente no se había 'alcanzado' esta madurez. Las metáforas léxicas 'catastróficas' como el abismo o alud y otras similares son comunes en el discurso político (Achugar 2009; Vasilachis de Gialdino 2007, entre muchos otros), y desempeñan un papel relevante en la construcción de las representaciones sociales en el discurso ${ }^{4}$.

El pasado se cosifica, plantearía Martin (2002, 2007), y esta cosificación del tiempo es característica del discurso de la historia. La tecnicalidad de la historia precisa considerar la secuenciación de las actividades, por lo cual se construyen cronologías en las que los autores conceptualizan diferentes tipos de tiempos, no todos con la misma prominencia en el discurso. La temporalidad típicamente se realiza mediante frases preposicionales de ubicación temporal colocadas en posición inicial en la oración. La cosificación del tiempo y su construcción en fases permite la nominalización (Martin 2007) facilitando, como se ha identificado en la reconstrucción de la evidencia en el Informe Valech (Oteíza en prensa), la representación de la actividad como un fenómeno abstracto.

Lo que "termina" se marca con el reconocimiento y la reivindicación de las víctimas, aun cuando el camino de sanación no ha curado el anhelo, el "reclamo" de justicia del pasado de miles de chilenos que han sido tibiamente escuchados. Sólo se ha recuperado parte de la verdad y los victimarios siguen en el espeso silencio de la impunidad representados como actores sociales colectivos (Dina, CNI, agentes del Estado). Lo que termina es el silencio en torno al sufrimiento de las víctimas, las que reconocemos como sociedad, así como reconocemos las graves consecuencias que la tortura tuvo en sus vidas y en las de sus familias. En suma, el discurso se enfoca en la reivindicación de las víctimas haciendo evidente que la memoria es selectiva.

El camino implica un proceso de 30 años que se dividen en capítulos y pasos como puede apreciarse en la Figura 6, en la que se ilustra la representación simbólica de la trama temporal del discurso y las principales valoraciones que desde el sistema de

\footnotetext{
${ }^{4}$ Así también sostiene Achugar (2009) en relación a la construcción de la memoria histórica de la dictadura de los militares uruguayos; el 'pasado' se representa con un alto nivel de conflicto y se recurre a metáforas de la enfermedad -muy documentadas en el discurso político- como la de un cuerpo que sufre una enfermedad. Las patologías son utilizadas para justificar la represión, sostiene Achugar, "permitiendo que los militares, mediante la elección de determinadas configuraciones lexicogramaticales y discursivas, legitimen una memoria del periodo de la dictadura y de la institución" (2009: 290).
} 
Figura 6

Construcción de la temporalidad en el Prólogo de Ricardo Lagos

\begin{tabular}{|c|c|c|c|c|c|}
\hline \multicolumn{6}{|c|}{ Representación simbólica valorativa de la trama temporal } \\
\hline \multirow[b]{2}{*}{$\begin{array}{l}\text { Fases } \\
\text { temporales }\end{array}$} & \multicolumn{3}{|c|}{ Pasados } & \multirow{2}{*}{\begin{tabular}{|l|}
\multicolumn{1}{|c|}{ Presente } \\
"hoy" (2004) \\
Personalización del \\
argumento
\end{tabular}} & \multirow{2}{*}{\begin{tabular}{l}
\multicolumn{1}{c}{ Futuro } \\
Espacio de convivencia \\
democrática \\
asegurado.
\end{tabular}} \\
\hline & $\begin{array}{l}\text { "Tradición histórica } \\
\text { de Chile" } \\
\text { (de las instituciones } \\
\text { armadas y del Estado) }\end{array}$ & $\begin{array}{l}\text { "quiebre de } \\
\text { la institución } \\
\text { democrática" } \\
\text { (Abismo/ pérdida de } \\
\text { rumbo) }\end{array}$ & $\begin{array}{l}\text { "30 años de silencio" } \\
(1973-2003)\end{array}$ & & \\
\hline $\begin{array}{l}\text { Valoración } \\
\text { desde el } \\
\text { dominio } \\
\text { semántico } \\
\text { de Actitud }\end{array}$ & $\begin{array}{l}\text { Estima Social positiva } \\
\text { [Normalidad] } \\
\text { Sanción Social positiva } \\
\text { [Corrección: tradiciones } \\
\text { democráticas] } \\
\text { Apreciación } \\
\text { [Valoración } \\
\text { Social positiva] }\end{array}$ & $\begin{array}{l}\text { Estima Social } \\
\text { negativa [Normalidad } \\
\text { negativa: } \\
\text { pérdida de rumbo] } \\
\text { Sanción Social } \\
\text { negativa } \\
\text { [Corrección negativa: } \\
\text { horrores del pasado / } \\
\text { abismo] } \\
\text { Afecto negativo } \\
\text { [temor, inseguridad] }\end{array}$ & $\begin{array}{l}\text { Estima Social negativa } \\
\text { Apreciación } \\
\text { Social negativa } \\
\text { Afecto negativo } \\
\text { [temor, inseguridad] }\end{array}$ & $\begin{array}{l}\text { Sanción Social positiva } \\
\text { [madurez moral de los } \\
\text { chilenos/ fortaleza moral } \\
\text { de los chilenos y de las } \\
\text { víctimas] }\end{array}$ & $\begin{array}{l}\text { Estima Social positiva } \\
\text { [Normalidad: } \\
\text { armonía, consenso, } \\
\text { reconciliación] } \\
\text { Sanción Social positiva } \\
\text { [Corrección: } \\
\text { recuperación de } \\
\text { la dignidad de las } \\
\text { víctimas] }\end{array}$ \\
\hline \multirow{12}{*}{$\begin{array}{l}\text { Instancias } \\
\text { temporales }\end{array}$} & & $\begin{array}{l}\text { Septiembre de } 1973 \text { y } \\
\text { marzo de } 1990\end{array}$ & $\begin{array}{l}\text { entonces (12 de agosto } \\
\text { de 2003) }\end{array}$ & 31 años después & ....un mismo destino \\
\hline & $\begin{array}{l}\text {...retomemos la senda } \\
\text { de siempre }\end{array}$ & $\begin{array}{l}\text { Un día cayó (abismo al } \\
\text { que cayó Chile) }\end{array}$ & $\begin{array}{l}\text { ¿cómo pudimos vivir } 30 \\
\text { años de silencio? }\end{array}$ & $\begin{array}{l}\text { Una comunidad que } \\
\text { puede, ahora más que } \\
\text { antes, mirar de frente y } \\
\text { sin temores... }\end{array}$ & Próximos 50 años \\
\hline & & horrores del pasado & $\begin{array}{l}\text { Todo ello [las vidas } \\
\text { quebradas, las familias } \\
\text { destruidas... ] estuvo } \\
\text { cubierto durante mucho } \\
\text { tiempo por un espeso e } \\
\text { insano silencio. }\end{array}$ & $\begin{array}{l}\text { Un país que hoy es más } \\
\text { fuerte }\end{array}$ & $\begin{array}{l}\text { a estos compatriotas y } \\
\text { sus familias se les trató } \\
\text { de arrebatar su dignidad } \\
\text { para siempre }\end{array}$ \\
\hline & & $\begin{array}{l}\text { en esos oscuros días } \\
\text { del ayer }\end{array}$ & $\begin{array}{l}\text { Ha sido un largo, } \\
\text { complejo, paciente } \\
\text { camino }\end{array}$ & $\begin{array}{l}\text { tantos años después de } \\
\text { los hechos }\end{array}$ & \\
\hline & & $\begin{array}{l}\text { en un momento del } \\
\text { pasado }\end{array}$ & $\begin{array}{l}\text {...en un determinado } \\
\text { momento parecieron } \\
\text { irreparables. }\end{array}$ & $\begin{array}{l}\text { [quiebre vital de las } \\
\text { víctimas] hasta el } \\
\text { presente }\end{array}$ & \\
\hline & & $\begin{array}{l}\text { los momentos más duros } \\
\text { [de la dictadura] }\end{array}$ & $\begin{array}{l}\text { Primer paso } \\
\text { (Comisión de Verdad y } \\
\text { Reconciliación, Informe } \\
\text { Rettig) 1991, Presidente } \\
\text { Aylwin }\end{array}$ & $\begin{array}{l}\text { daños que permanecen } \\
\text { hasta hoy }\end{array}$ & \\
\hline & & este pasado & $\begin{array}{l}\text { Otro paso (mesa de } \\
\text { Diálogo instalada por el } \\
\text { Presidente Frei) }\end{array}$ & treinta años después & \\
\hline & & & $\begin{array}{l}\text { El camino de } \\
\text { las reparaciones } \\
\text { para las víctimas } \\
\text { (nominalización) }\end{array}$ & El año pasado & \\
\hline & & & Capítulo & Hoy & \\
\hline & & & $\begin{array}{l}\text { valioso proceso de } \\
\text { regeneración moral }\end{array}$ & $\begin{array}{l}\text { Hoy podemos mirar } \\
\text { con serenidad nuestro } \\
\text { pasado }\end{array}$ & \\
\hline & & & $\begin{array}{l}\text { El camino de hacernos } \\
\text { cargo del pasado }\end{array}$ & $\begin{array}{l}\text { Hemos recuperado } \\
\text { la necesaria armonía } \\
\text { entre la sociedad y sus } \\
\text { instituciones armadas. }\end{array}$ & \\
\hline & & & Camino/senda/ capítulo & Se terminó el silencio & \\
\hline
\end{tabular}

ACTITUD van organizando el argumento. Así, las valoraciones se articulan junto con las fases temporales del pasado ya que cada fase se construye en el discurso con una valoración determinada de juicio de Estima Social y Sanción Social, Apreciación y Afecto. La temporalidad se expresa en el discurso en adjuntos, frases preposicionales, 
adjetivos, frases nominales, tiempos, modos y aspectos verbales. Los significados experienciales de actitud aparecen graduados.

\section{Conclusiones}

La reconstrucción de las memorias en el discurso de informes oficiales sobre violaciones a los derechos humanos en Chile se realiza, en parte, por la representación simbólica valorativa de la trama temporal. De esta manera, las fases temporales se van constituyendo en el discurso desde determinadas valoraciones de Actitud de juicios de Estima y Sanción Social, de Apreciación y de Afecto con diferentes niveles de compromiso.

En el análisis de la inclusión de la voz de los autores en los Informes Rettig y Valech hemos examinado previamente el funcionamiento de recursos lexicogramaticales como la modalización, modulación, polaridad negativa y nominalizaciones en conjunto con otros recursos de extravocalización (inserción y asimilación, Informe Valech) para comprender mejor desde qué perspectivas se recontextualizan en estos documentos oficiales (Ministerio del Interior de Chile) la muerte, tortura y prisión política practicadas entre los años 1973 y 1990. Asimismo, hemos planteado que si bien las nominalizaciones pueden colaborar a la naturalización del discurso y a expresar con más fuerza la objetivación de lo social (una sociedad "blindada" diría Lechner, 2006), éstas pueden también funcionar como prominencias temáticas que se construyen discursivamente a partir de la inclusión de diferentes perspectivas y que son acompañadas en el discurso por valoraciones inscritas de los autores del documento.

Las políticas de la memoria de los gobiernos concertacionistas chilenos (19902009) se han circunscrito a "la medida de lo posible" (Presidente P. Aylwin, 1991) y a la denominada "democracia de los acuerdos" guiada por el principio de gobernabilidad. Consecuentemente, la verdad y la justicia han estado supeditadas a "lo posible", como también lo afirma el ex Presidente R. Lagos en el Prólogo del Informe Valech en relación a las medidas de reparación material y simbólica a las víctimas de las violaciones a los DDHH durante 1973-1990. En ambos informes oficiales es posible apreciar un discurso de reivindicación de las víctimas y en donde los perpetradores son relegados a la categoría de "villanos" pero sin nombre como sostiene Hiner (2009) y todavía sabemos muy poco acerca de los miles de civiles, policías y personal militar que participaron en la represión.

La metáfora del camino de R. Lagos -a la que también han recurrido otros líderes políticos- implica una llegada, un destino, un término de ese caminar. Decretar el cierre de un proceso de sanación anula, al menos desde el discurso oficial y las políticas concretas, la posición de quienes no ven un término del problema de los DDHH, ni la obtención de verdadera justicia. Este contexto de "cierre" construido por R. Lagos en relación a la violación a los DDHH en Chile plantea una alternativa frente al silencio de la tortura, pero finalmente se desecha de manera definitiva con la paradoja de que son las víctimas quienes solicitaron dicho silencio para proteger su intimidad. En términos de creación de representaciones sociales se aprecia particularmente una construcción de las víctimas desde una valoración de Actitud de Sanción Social positiva dado que tienen el valor de romper el silencio; ellas son representadas 
de manera generalizada y activa en el discurso como una entidad nominalizada. Los victimarios son relegados a representaciones colectivas y sin que se asocien a ellos juicios morales explícitos (inscritos) de Sanción Social. De esta forma, el discurso de Lagos se cierra sin cerrar un capítulo de nuestro pasado.

El ex Presidente P. Aylwin pide perdón a los chilenos y enfatiza que todos debemos asumir nuestra responsabilidad. El ex Presidente R. Lagos alaba la fortaleza moral de los chilenos y declara que se ha descorrido el velo del silencio (de la tortura masiva, institucionalizada y sistemática por parte de los agentes de Estado durante la dictadura militar), que sanamos nuestras heridas, que recuperamos la armonía. De acuerdo con Lechner, se rigidiza la memoria del pasado, lo que permite "dar vuelta la página de la historia" (Augoustinos et al. 2002; Wodak y De Cilia 2007, entre otros). Así, la representación del tiempo social permite la escenificación del pasado y la evaluación del mismo desde una perspectiva determinada que naturaliza lo social, propicia una sacralización de la historia y legitima "una" memoria social.

Las políticas de la memoria no sólo involucran la representación del pasado como sostiene Achugar (2009), sino que también "la recreación de las relaciones sociales y de la mantención/construcción de las identidades políticas" (2009: 292). El ex Presidente Ricardo Lagos construye una voz valorativa de Adjudicador (valoraciones de juicio de Sanción y de Estima Social) para elaborar su argumento del "proceso de sanación" . El silencio se relaciona con el pasado, con los lugares secretos de tortura que se ubicaron a lo largo de todo el país, al silencio de las víctimas de prisión y de tortura, al silencio de la dictadura y su régimen de terror, esto es lo que "termina" según el discurso presidencial y podemos vivir en armonía (Hemos recuperado la necesaria armonía). El silencio ha terminado debido a que somos más fuertes como sociedad. Sin embargo, como sociedad fragmentada, todavía convivimos, según Lechner (2006), con los silencios de las memorias acerca de nuestro pasado traumático, lo que dificulta una reconciliación real entre los chilenos y, por lo mismo, a pesar de las políticas de reconciliación que el ex Presidente Lagos sostiene, la nación chilena continúa profundamente herida y dividida (Stern 2006; Lechner 2006; Hiner 2009).

\section{ObRas CITADAS}

Achugar, M. 2008. What we remember: the construction of military memory. Amsterdam: John Benjamins.

. 2009. "Constructing the past and constructing themselves: The Uruguayan military's memory of the dictatorship". Critical Discourse Studies, 6 (4): 283-295.

Augoustinos, M.A. Lecouteur, y J. Soyland. 2002. 'Self-sufficient Arguments in Political Rhetoric: Constructing Reconciliation and Apologizing to the Stolen Generations', Discourse \& Society, 13 (1): 105-142.

Bajtín, M. 1991. The Dialogic Imagination. Austin: University of Texas Press.

Burgueño N., Claudia. 2006. "Relaciones de intertextualidad en discursos políticos presidenciales". Lingüística y Literatura 17: 221-241.

\footnotetext{
5 C. Burgueño (2006), en su análisis de seis discursos presidenciales concertacionistas (Aylwin Azócar, Frei Ruiz-Tagle y Lagos Weber) y su posicionamiento en relación a la violación a los DDHH durante la dictadura militar de 1973-1990, también considera que las voces convocadas por Lagos están marcadas por una voz de autoridad moral.
} 
Coffin, C. 2002. 'The Voices of History: Theorizing the Interpersonal Semantics of Historical Discourses", Text 22 (4), 503-528.

2003. "Reconstruals of the Past - Settlement or invasion? The role of Judgement Analysis", en: J. R. Martin \& R. Wodak. (eds.). Re/reading the Past Amsterdam/Philadelphia: John Benjamins Publishing Company.

- 2006. Historical discourse: the language of time, cause and evaluation. London, New York: Continuum.

Fairclough, N. 2003. Analysing Discourse. Textual analysis for social research. London/New York: Routledge.

Halliday, M.A.K. 1994. An Introduction to Functional Grammar. London: Edward Arnold.

Halliday, M.A.K. y C. Matthiessen. 2004. An Introduction to Functional Grammar. London: Edward Arnold. Third Edition.

Hiner, H. 2009. "Voces soterradas, violencias ignoradas. Discurso, violencia política y género en los Informes Rettig y Valech". Latin American Research Review, 14 (3): 50-74.

Hood S. y J.R. Martin. 2007. "Invoking attitude: the play of graduation in appraising discourse". En Continuing Discourse on Language. A functional perspective. Volume 2. R. Hasan, Ch. Matthiessen y J. Webster (Eds.), pp. 739-764.

Hunston, S. y G. Thompson. 2000. Evaluation in Text. Oxford: Oxford University Press.

Jelin, E. 2002. Los trabajos de la memoria. Madrid: Siglo Veintiuno de España Editores S.A.

Kaplan, N. 2007. "La teoría de la valoración: un desarrollo de los estudios sobre la evaluación en el lenguaje”. En Análisis del discurso ¿Por qué y para qué?, A. Bolívar (Coord.), Caracas: Universidad Central/ Los Libros de El Nacional.

Lechner, N. 2006. Las sombras del mañana. La dimensión subjetiva de la política. Santiago de Chile: LOM.

Martin, J.R. 1997. "Analysing Genre: Functional Parameters", en: F. Christie \& J. R. Martin (eds.). Genre and Institutions: Social Processes in the Work Place and School. London: Continuum.

—. 2000. "Beyond Exchange: Appraisal Systems in English", en: S. Hunston \& G. Thompson. (eds.). Evaluation in Text. Oxford: Oxford University Press.

—. 2002. "Writing History: Construing Time and Value in Discourses of the Past", en: M. Schleppegrell \& M. C. Colombi. (Eds.). Developing Advanced Literacy in First and Second Languages: Meaning with Power. Mahwah, NJ: Lawrence Erlbaum Associates.

—. 2003a. "Introduction", Text, 23(2), Special Issue. Negotiating Heteroglossia: Social Perspectives on Evaluation. Macken-Horarik, M.\& J.R. Martin. Eds.

—. 2003b. "Making history: Grammar for interpretation", en: J.R. Martin \& R. Wodak. (eds.).Re/reading the Past. Critical and functional perspectives on time and value. Amsterdam/Philadelphia: John Benjamins Publishing Company.

—. 2007. "Construing knowledge: a functional Language perspective". En Language, Knowledge and Pedagogy. Functional Linguistic and Sociological Perspectives. F. Christie y J.R. Martin (Eds.). London: Continuum.

- 2008. Terderness: Realisation and Instantiation in a Botswanan Town. In Systemic Functional Linguistics in Use. Odense Working Papers in Language and Communication. Vol. 29, pp. 30-58

Martin, J.R. y D. Rose. 2003, 2007. Working with Discourse. London: Continuum.

- 2008. Genre relations. Mapping culture. London: Equinox.

Martin, J.R. y White, P. 2005. The Language of Evaluation. Appraisal in English. New York: Palgrave Macmillan.

Maton, K. 2007. "Knowledge-knower structures in intellectual and educational fields". En Language, Knowledge and Pedagogy. Functional Linguistic and Sociological Perspectives. F. Christie y J.R. Martin (Eds.). London: Continuum. 
Oteíza, T. 2003. "How Contemporary History is Presented in Chilean Middle School Textbooks", Discourse \& Society, 14(5): 639-660.

2006. El discurso pedagógico de la historia. Un análisis lingüístico sobre la construcción ideológica de la historia de Chile (1970-2001). Santiago, Chile: Frasis editores.

—. 2009a. "Solidaridad ideológica en el discurso de la historia: tensión entre orientaciones monoglósicas y heteroglósicas". Revista Signos. Estudios de Lingüística 42 (70): 219244.

2009b. "Evaluative patterns in the official discourse of Human Rights in Chile: giving value to the past and building historical memories in society". Delta 25 , número especial, pp. 609-640.

. "De la conspiración de silencio al reconocimiento de voces alternativas. Las violaciones a los derechos humanos en Chile según el Informe Valech". En Revista Latinoamericana de Estudios del Discurso, ALED (en prensa).

Oteíza, T, y D. Pinto. 2008. "Agency, Responsibility and Silence in the Construction of Contemporary History in Chile and Spain", Discourse \& Society, 19 (3): 333-358.

Stern, S. 2006. Remembering Pinochet's Chile. On the Eve of London 1998. Durkam \& London: Duke University Press.

Stubbs, J. 2009. "Subordination, competing interests and the challenge of communication in restorative justice practices, through the lens of gendered violence". Presentación en la conferencia: Towards Restorative Justice: The Challenges, Promises and Processes of a New Paradigm, 7-9 diciembre, University of Sydney.

Thompson, G. y S. Hunston .2000. "Introduction”, en: Hunston, S. y Thompson, G. (eds.), Evaluation in Text. Oxford: Oxford University Press.

Vasilachis de Gialdino, I. 2007. "Condiciones de trabajo y representaciones sociales. El discurso político, el discurso judicial y la prensa escrita a la luz del análisis sociológico-lingüístico del discurso". Discurso y Sociedad 1 (1): 148-187.

van Dijk, T. 2009. Discurso y Poder. Barcelona: Editorial Gedisa.

van Leeuwen, T. 1996. "The representation of social actors", en: Texts and Practices. Readings in Critical Discourse Analysis. London: Routledge.

— 2008. Discourse and Practice. New Tools for Critical Discourse Analysis. Oxford: Oxford University Press.

White, P.R.R. 2000. The appraisal website. http://www.Grammatics.com/appraisal/. Actualizado: 5 de marzo de 2005.

White, P.R.R. 2003. "Beyond modality and hedging: A dialogic view of the language of intersubjective stance", Text, 23 (2): 259-284.

Wodak, R. y De Cilia. 2007. "Commemoring the past: the discursive construction of official narratives about the 'Rebirth' of the Second Austrian Republic", Discourse \& Communication, 1 (3): 337-363. 
